\title{
Author Correction: Vibrio spp. infections
}

Craig Baker-Austin, James D. Oliver, Munirul Alam, Afsar Ali, Matthew K. Waldor, Firdausi Qadri and Jaime Martinez-Urtaza

Correction to: Nature Reviews Disease Primers https://doi.org/10.1038/s41572-018-0005-8, published online 12 July 2018.

The originally published article contained an error in the Introduction section, in which Staphylococcus aureus was incorrectly reported as Streptococcus aureus. This error has been corrected in the HTML and PDF versions of the manuscript.

https://doi.org/10.1038/s41572-021-00250-9| Published online: 19 February 2021

(๑) Springer Nature Limited 2021 